\title{
Israel Tackles Conservation
}

\author{
By K. R. Ashby
}

Intensive agricultural and urban development by Jewish settlers, coupled with a population explosion among the Bedouin Arabs (and their goats), have brought rapid changes to both the fauna and fora of Israel. While the increase in suburban gardens has benefited some birds, the use of pesticides has exterminated others, and the use of the Negev for army training brought near disaster to the desert gazelle. But the Jewish people are conservationminded. Dr. Ashby, recently returned from Israel, describes how they are tackling the task of making five per cent. of their country into nature reserves.

A LTHOUGH a small country, Israel has a rich variety of animals $A$ and plants as it is a meeting point for species of Mediterranean, steppe, North African and even Central African affinities. There is, too, a great diversity of habitat owing to the wide range of topographical and climatic conditions. In the north the climate is Mediterranean, with substantial winter rainfall in the hill country of Galilee. In the south and south east there are extreme desert conditions, and the Dead Sea and the Jordan Valley bring a tongue of tropical temperatures along the east side of Israel right up to the Syrian border. ${ }^{15}$ Another important influence on the fauna and flora is the long history of settled civilisation. The substantial drop in human population during the 2000 years up to the 19 th century was probably the result of a decline in productivity due to overgrazing and other forms of unsuitable land use, although compared with some other countries of the Middle East and the Mediterranean zone the damage appears to have been relatively slight.

Before 1914, serious losses of species seem to have been confined to large animals such as the lion, bear, crocodile, fallow and roe deer, oryx and ostrich. The first world war brought serious damage to the remaining stands of large species of oak, as in Jordan, ${ }^{52}$ but up to 1930 much of the country, including the coastal plain, was still in a fairly natural condition, with large areas of reed swamp adjoining the rivers and extensive tracts of sandy soils uncultivated.

The immigration of Jewish refugees resulted in intensive settlement wherever modern techniques of agriculture and fish culture could be used. The exodus of most of the non-nomadic Arabs in 1948 reduced the grazing pressure in the hill country, with the result that the evergreen low forest, or charappal, dominated mainly by Quercus calliprinos and Pistacia palestina has increased in vigour. The coastal plain, however, has been transformed into an agricultural landscape 


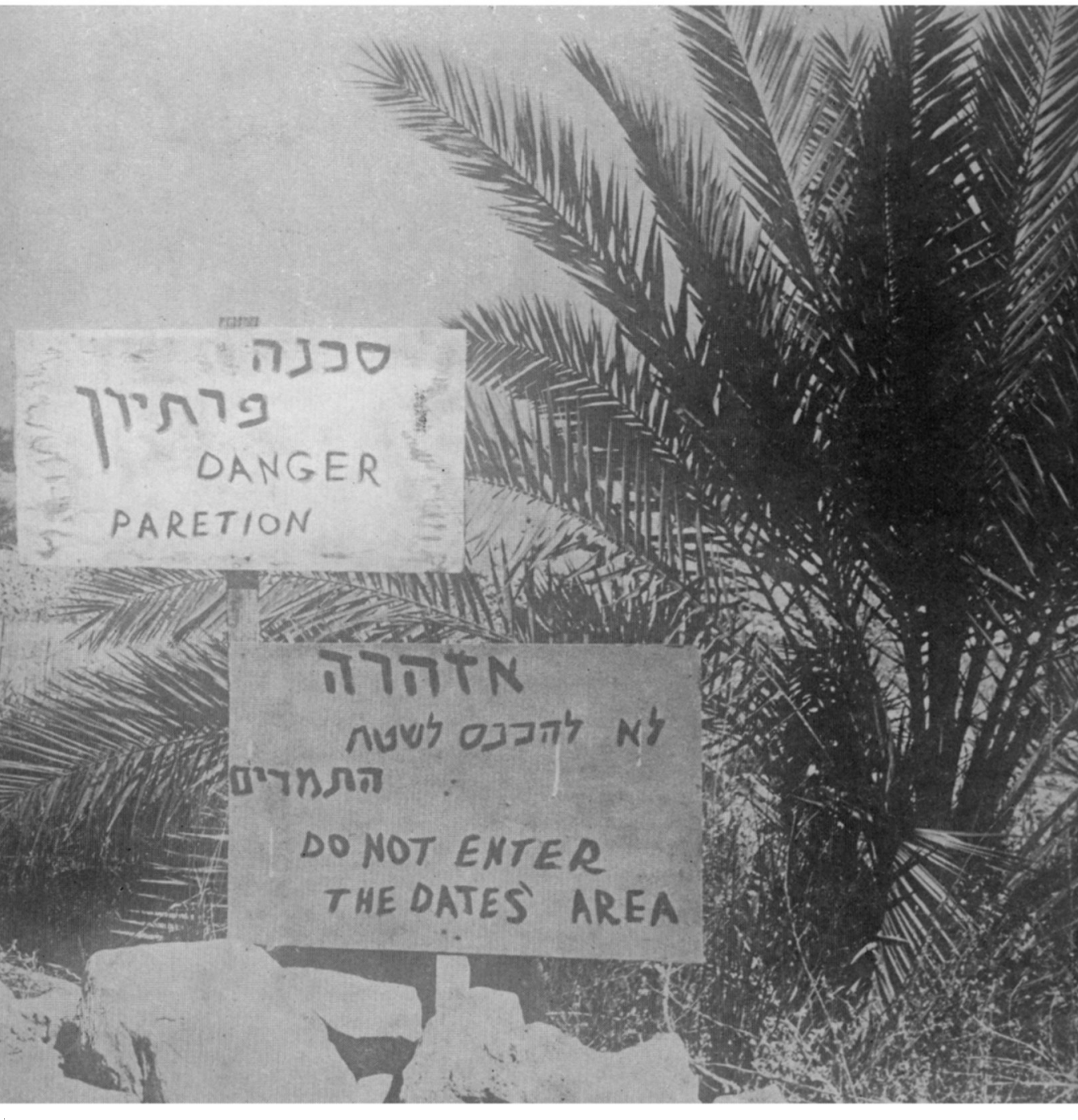

"BEWARE OF PARATHION"

Plate 14. The modern equivalent of the "Beware of the Bull" notice in Israel. The insecticide parathion, one of the organo-phosphorous poisons, has been sprayed on the young dates in a plantation on the edge of the Ein Gedi Nature Reserve. Photographs by K. R. Ashby 


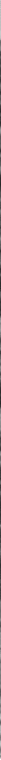

\section{Plate 15: The Charappal, the low evergreen forest of the hills, and the Kesii Valley. ISRAELI LANDSCAPES}

Plate 16 : Fields, windbreaks of cypress trees and fishponds in the coastal plain.

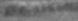




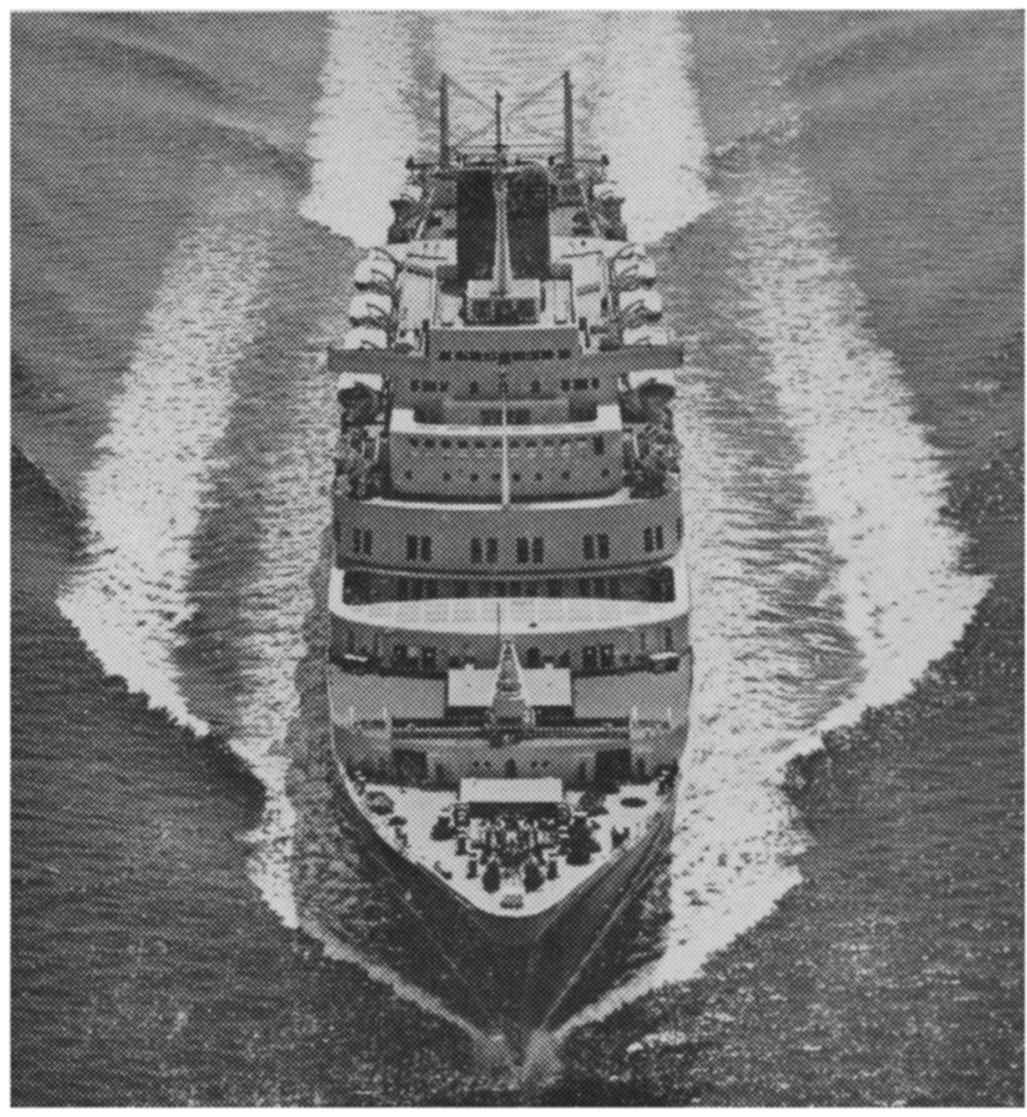

\section{Now, Fridays from Southampton TO CAPE TOWN IN UNDER 12 DAYS}

Union-Castle's Mail service between England and South Africa has been accelerated. Regular passenger sailings from Southampton on Fridays at 1 p.m: from Cape Town on Wednesdays at 4 p.m: calls always at Las Palmas, southbound and northbound, and sometimes Madeira as well. Details of this new service are in the new Fares and Sailings folder, obtainable from Travel Agents or from Union-Castle offices: at 19-21 Old Bond Street, London, W.1, and at Southampton, Birmingham, Leeds, Manchester, Glasgow, Cape Town, Port Elizabeth, East London, Durban, Johannesburg, Salisbury and Mombasa.

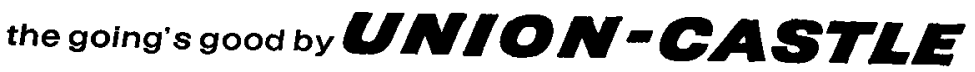

THE BIG SHIP WAY TO AFRICA 
resembling those of Western Europe in basic design, with field sizes comparable with those of East Anglia, an extensive system of windbreaks formed by eucalyptus and cypress, and orchards of citrus fruits covering large areas. Rainwater stored by the limestone of the hill country between the coastal plain and the Jordan has been exploited for irrigation and urban development to the point where water flow to the sea has been eliminated. River habitats on the coastal plain have virtually disappeared and most of the rivers are polluted by sewage. The swamps on the coastal plain and in the Upper Jordan Valley have been reclaimed for agriculture or converted into fish ponds. Irrigated agriculture will extend further south in the Beer Sheba area when the aqueduct bringing water from the Sea of Galilee comes into full use, but the main change in the arid zone of Israel is a population explosion of Bedouin Arabs. A final important development is the creation of a leafy suburbia round all settlements, the Israelis being remarkably liberal in the use of water to make pleasant surroundings to their homes.

These changes have had drastic but not always harmful effects on wild plants and animals. As in England, ${ }^{3}$ the increase in gardens, hedgerows and orchards has resulted in some birds, such as blackbirds and sunbirds, becoming more abundant. Mongooses are common round fish ponds, and jackals thrive as scavengers near settlements to the point of being a serious nuisance. A worse pest favoured by recent developments is the vole Microtus guntheri which removes grain from the ears of ripe corn and stores if underground.

Devastation Among Birds of Prey

Damage to the fauna is mainly due to side effects of the changes in land use, by far the most serious being the indiscriminate use of persistent pesticides, particularly thallium sulphate, used against Microtus, and chlorinated hydrocarbons sprayed in orchards against the Mediterranean fruit fly. Thallium sulphate has had devastating effects on birds of prey. The Egyptian vulture, previously common, has been almost exterminated and the griffon vulture much reduced in numbers. The other resident vultures, the bearded and lappet-faced, are rare inhabitants of the desert and not affected by this particular threat, but the lappet-faced has suffered from disturbance of nests and needs careful protection. Secondary poisoning has been equally serious among hawks and eagles. The spotted and imperial eagles, the kite and the marsh harrier have been exterminated, there are very few Bonelli's eagles, buzzards or lanner falcons remaining, and kestrels are much reduced in numbers. The least affected of previously common species is the short-toed eagle, which is a lizard eater. Deaths among the smaller birds through accumulation of persistent insecticides may have been as serious as in Great Britain or the United States, but there has so far been insufficient research to give a verdict. Losses amongst mammals have not been as serious as amongst birds, but nevertheless poisoning as a result of predators eating bait intended for 
jackals has almost eliminated other wild carnivores from settled areas. The Turkish sub-species of leopard still persists in small numbers in the wilder parts of Upper Galilee and a small dark sub-species is still present in the Jordan desert. The caracal is fairly common, but the hyena has become rare not only as a result of poisoning but because it is frequently killed on roads. Two subspecies of wolf are still represented, the normal one occurring locally in the north and a small subspecies in the desert. Fairly large herbivorous mammals still present in Israel are the boar, which is widespread but at a low population density, the common and the desert gazelles, and the ibex, there being about 800 of the last living on bare rocky areas including the mountains bordering the Dead Sea. Of the species of smaller mammals which are very rare the stone marten is in no danger as it lives in remote rocky country, and the honey badger is also not immediately threatened. The wild domestic cat has become rare because of extensive interbreeding with the tame variety.

\section{Conifers Destroy the Vegetation}

In a country such as Israel where intensive farming must have priority wherever there is fertile land, the wilder and more thinly populated areas are of particular importance in the conservation of plants and animals. It is therefore disturbing that there are serious threats to the charappal or maquis, covering 250,000 acres of hill country, which could more than undo recent gains resulting from the reduction in grazing pressure. At.present the more serious of these is afforestation with conifers, particularly Pinus halepensis, carried out by the Ministry of Agriculture. In principle, the restoration of a tree cover to areas where it has been removed by overgrazing is excellent. Ecologists in Israel, however, regard this sort of afforestation as a serious threat to wildlife, because the continuous blanket of young pines destroys all other vegetation, and much of the area afforested will not even produce a commercial crop of timber. On the desert fringe, trials are being made of methods, including tree planting, of restoring a vegetation cover; properly handled, this could greatly improve the habitat in these areas.

Paradoxically the other threat to the charappal is deliberate deforestation and shrub removal. This comes from the water conservation authorities, who claim that the evergreen shrubs and small trees cause the evaporation of about 5 in. more of the rainfall per year than if only herbaceous vegetation were present, and that an increase of 7 per cent. in the country's overall water resources would be achieved by their removal. Although this is contrary to generally held opinions concerning the effect of a tree cover on water conservation, the water authorities may have some grounds for their claim. For example, in Tanzania, in an area of porous soil with good storage in the underlying bed-rock, the East African Agricultural and Forestry Research Organisation found that removal of the natural forest cover and substitution of primitive agriculture greatly increased the supply 
of underground water. ${ }^{4}$ But the removal of all tree and shrub cover would certainly greatly reduce the attractiveness of the charappal habitat for a wide variety of plants and animals, and it is to be hoped that exhaustive experiments will be carried out before it is decided to clear any considerable area.

\section{The Arabs and their Coats}

The population explosion of the Bedouin Arabs, who in Israel at present number 60,000 , is a result of the introduction of modern medicine into a society where high fecundity is a major status symbol. The Arabs are mainly concentrated on the loess soils near Beer Sheba, where they practice a primitive form of dry farming. By the early autumn their other status symbol, the immense flocks of goats, have eaten all the stubble and surface vegetation and are living on the roots. In most circumstances such intense overgrazing would cause widespread and severe gully erosion; in fact erosion is relatively limited, because the underlying limestone absorbs even heavy rainfall. Nevertheless it is unlikely that the habitat can stand an increase in this type of occupation, and there is a serious threat of increased Bedouin pressure in the desert to the south, which is already overgrazed, and on the Judaean hills to the north. If this materialises, the wildlife of these areas would be directly threatened since the Bedouin are permitted to carry rifles (for self defence against border raids and blood feuds) and their use is difficult to control. The other important human pressure in the arid zone results from the use of the Negev for army training. Inevitably, soldiers with little to occupy their leisure are tempted to shoot the wildlife. The most seriously threatened species is the desert gazelle Gazella dorcas the decline in which is the probable cause of the extinction of the cheetah in Israel.

Prior to 1950 there had been practically no attempts at conservation. Like the previous Turkish administration, the British mandatory government between the wars did almost nothing. Since then progress has been rapid, especially since the creation of the Nature Protection Authority in 1964. The spearhead of the conservation movement, the Society for the Protection of Nature in Israel, was formed in 1954 and now has 10,000 members in a population of 2.5 million. Today it is strong enough to accept financial support from the Ministries of Education and the Interior without prejudicing its independence as a voluntary society. Great emphasis has been put on achieving close contacts with the education authorities, particularly at local level, and every opportunity is taken to ensure that Israeli children acquire a good knowledge of the animals and plants of their country and feel personally responsible for helping to protect them. Official Ministry of Education support for this aim has now been achieved and it is anticipated that soon every school child will attend a course at one of the Society's field centres, which are organised much on the lines of those of the Field Studies Council in England. At present the Society runs five of these. It eventually hopes to have about twenty, 
and recently $£ 100,000$ was collected for a new centre at Ein Gedi. The job of instructor and warden is recognised as national service in lieu of service in the armed forces. The Society also organises excursion parties, principally for young people at weekends, to areas of biological and scenic interest. These excursions have greatly helped the Society's funds and membership, and their scale is increasing rapidly.

The Society now has an impressive list of achievements. The year after it was formed it was made illegal to kill any bird or mammal, except certain game species in the open season, plus a small number of pest species. In 1964 protection was extended to lower vertebrates such as the soft-shelled turtle, and it was made illegal to dig up or sell rare plants. In the same year the use of thallium sulphate as a pesticide was forbidden. This particular victory cannot be regarded as final, as some of the substitute poisons are objectionable. The killing of the desert gazelle has been checked following intervention with the army authorities, and a survey of this gazelle in the Arava (rift) valley north of Eilat, in which I took part, produced a count of about 300 , considerably more than had been feared. The conservation movement has been greatly aided by Tel Aviv University, which gave Dr. A. Zahavi leave on full pay for several years to direct the Society for the Protection of Nature. Dr. Zahavi has recently become head of an Institute of Conservation in the University.

But even the best organised voluntary society cannot achieve effective conservation unaided. The need for a statutory Nature Conservancy has always been stressed, and the necessary legislation was passed in 1964. The Society is now pressing ahead in conjunction with the Nature Conservancy and the local authorities with the designation of reserves. It is intended that 5 per cent. of the area of Israel will become nature reserves. By the end of 1964 sixty had been designated, including the Huleh swamp in the upper Jordan Valley and the coral reef of Eilat. Reserves in the Negev and the Dead Sea area will eventually cover 120,000 acres, including the very important canyon and oasis at Ein Gedi with its central African affinities, lying to the west of the Dead Sea near the Jordan frontier.

In northern Israel the immediate prospect is 50,000 acres, and the ultimate aim is 80,000 acres. Apart from the swamp and freshwater reserves at Huleh, and the Ma'ayan Mikhael fishponds near the coast, the main areas involved include the limestone valleys and Mount Meron in north-west Galilee, Mount Carmel near Haifa where there is the only remaining natural pine forest in Israel, the remaining stands of high oak forest in Galilee, representative portions of the Judaean Hills, Mount Gilboa, and the sand dunes of the coastal plain. The interest of these last is the North African desert fauna and flora which extend northwards along them to varying degrees. The coast is seriously threatened by inadequately controlled suburban and seaside chalet development, a danger which is now beginning to affect the shores of the Sea of Galilee as well, and the Department of Landscaping is trying to organise planning boards to control building in sensitive areas. 
Acknowledgments

I should like to thank the staff of the Zoology Department at Tel Aviv University and both the Zoology and Botany Departments at Jerusalem University, together with the wardens of the Society for Protection of Nature. With the minimum of notice it was arranged that I should join in a wide variety of biological activities which took me into all parts of the country. In particular I must thank Professor Mendelssohn and Dr. Zahavi for playing a central part in the organising, and for their patience in providing me with information concerning conservation problems and a variety of other aspects of progress in biology in Israel. The visit was financed by grants from the Royal Society, the British Council and the Durham University Research Fund.

REFERENCES

1. BODENHEIMER, F. S. (1935). Animal Life in Palestine. Jerusalem, Mayer.

2. MOUNTFORT, G. (1964). Disappearing wildlife and growing deserts in Jordan. Oryx, 7: 229-232.

3. NICHOLSON, E. M. (1951). Birds and Men. London, Collins (New Naturalist).

4. PEREIRA, M. C., DAGG, M., and HOSEGOOD, P. H. (1962). The water-balance of the cultivated and control catchments, p. 118-122 in Hydrological effects of changes in land use in some East African catchment areas. Special issue of E. Afr. agric. for J. 27.

5. ZOHARY, M. (1962). Plant Life in Palestine. New York, the Ronald Press Co.

\section{Flowers from Morocco to Israel}

With so many thousands of people holidaying in the Mediterranean area each year, and a growing proportion of them interested in the wild flowers they see there, it is astonishing that a book like Flowers of the Mediterranean, by Oleg Polunin and Anthony Huxley (Chatto and Windus, 42s.). has not been written before. I know of nothing else in English illustrated in colour since 19:14. The authors make an excellent partnership, for the area they cover stretches from Morocco to Israel, and it is no mean feat to find two people capable of covering 'such an area adequately.

Of course the number of plants they are able to inolude is only a com. paratively small proportion of the whole; upwards of 700, of which 311 are illustrated by colour photographs taken by the authors and another 128 in attractive line drawings by Barbara Everard. I must confess that excellent though many of the photographs are, I do not in general find the arrangement of them in little square boxes on the page as aesthetically attractive as a good colour plate. On the other hand, it cannot be denied that from the purely utilitarian point of view, a well chosen photograph, as many of these are, is often as good as, if not better than, a colour painting of the same plant. I have only had one chance so far of using the book in the field, and it enabled me to identify almost all of the exiguous floral display that Attica offers in mid-December. I am confident that every lover of the wild flora of the Mediterranean will in future automatically take and use this book on his or her visits to that delectable region. 